ANL-7102

Metals, Ceramics, and

Materials (TID-4500)

AEC Research and

Development Report

ARGONNE NATIONAL LABORATORY

9700 South Cass Avenue

Argonne, Illinois 60439

GROWTH AND ANNEALING OF EVAPORATED

ALUMINUM-SILICON FILMS

by

R. K. Hart and D. G. Pilney

A Report of Metallurgy Program 10.2.2

Portions of the material in this report have appeared in the following Metallurgy Division Progress Report:

$\frac{\text { Number }}{\text { ANL-6516 }} \quad \frac{\text { Pages }}{312-313}$

November 1965

RELEASED FOR ANNOUNCEMENT

IN NUCLEAR SCIENCE ABSTRACTS

Operated by The University of Chicago

under

Contract W-31-109-eng-38

with the

U. S. Atomic Energy Commission 


\section{DISCLAIMER}

This report was prepared as an account of work sponsored by an agency of the United States Government. Neither the United States Government nor any agency Thereof, nor any of their employees, makes any warranty, express or implied, or assumes any legal liability or responsibility for the accuracy, completeness, or usefulness of any information, apparatus, product, or process disclosed, or represents that its use would not infringe privately owned rights. Reference herein to any specific commercial product, process, or service by trade name, trademark, manufacturer, or otherwise does not necessarily constitute or imply its endorsement, recommendation, or favoring by the United States Government or any agency thereof. The views and opinions of authors expressed herein do not necessarily state or reflect those of the United States Government or any agency thereof. 


\section{DISCLAIMER}

Portions of this document may be illegible in electronic image products. Images are produced from the best available original document. 


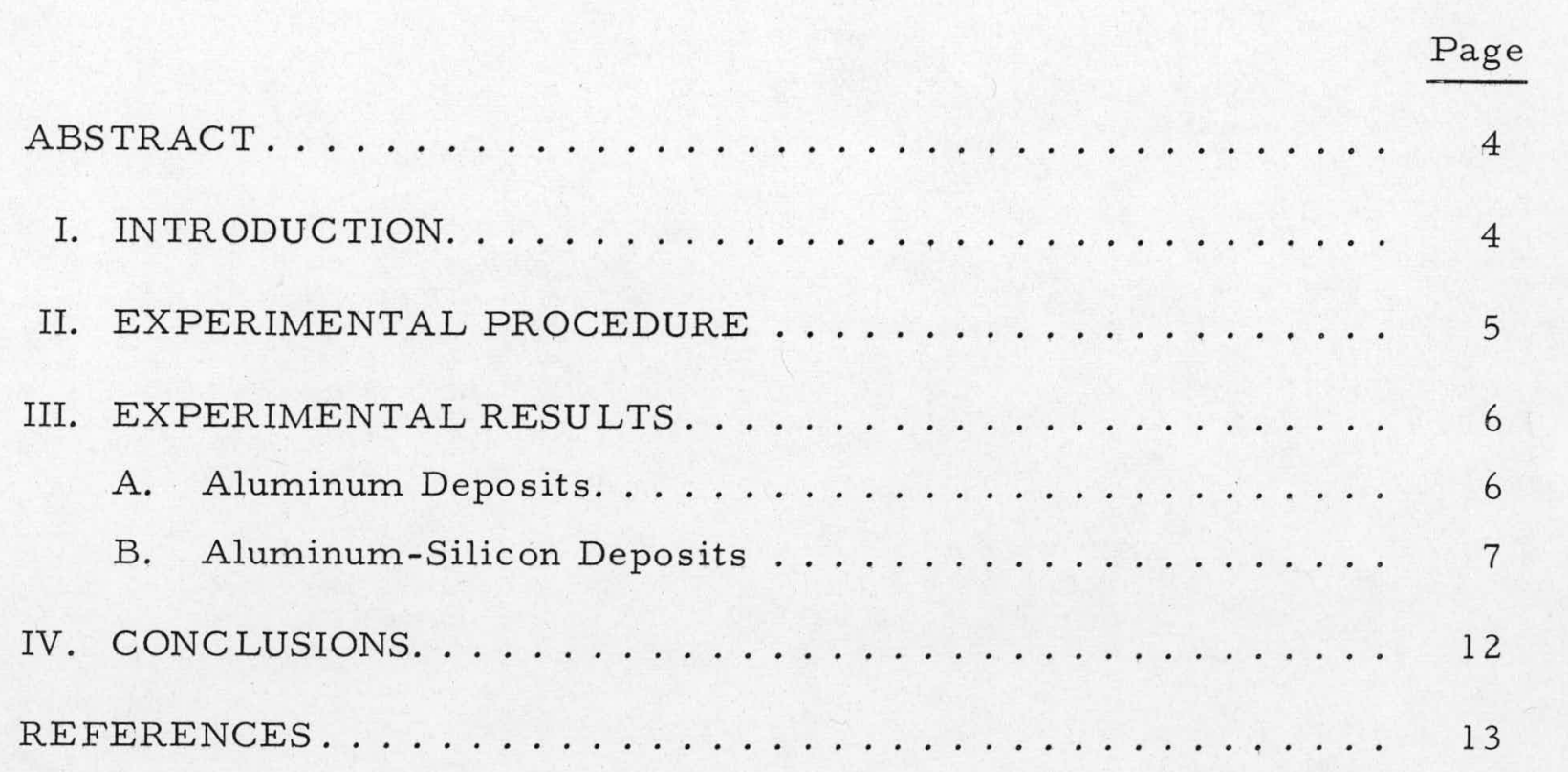




\section{LIST OF FIGURES}

No.

Title

Page

1. Aluminum Evaporated onto Rock Salt at $450^{\circ} \mathrm{C} \ldots \ldots . \ldots$

2. Selected-area Diffraction Pattern from Film Shown in Fig. 1.. 7

3. Aluminum-1\% Silicon Alloy on Rock Salt at $450^{\circ} \mathrm{C} \ldots \ldots 7$

4. Selected-area Diffraction Pattern from Film Shown in Fig. 3.. 8

5. Schematic Diagram of Pattern Shown in Fig. 4........ 8

6. High Magnification of Aluminum-1\% Silicon Alloy Showing Enhancement of Grain Boundaries by Dislocations ........

7. Aluminum-10\% Silic on Alloy Evaporated onto Rock Salt

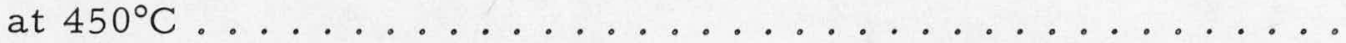

8. Aluminum-5\% Silicon Alloy Evaporated onto Rock Salt

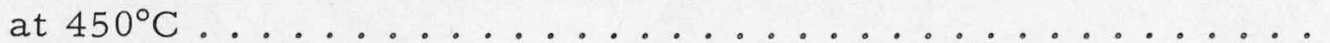

9. Aluminum-10\% Silicon Evaporated onto Rock Salt at Room Temperature and Then Heated on Hot Stage at $550 \pm 20^{\circ} \mathrm{C} \ldots$

10. Selected-area Diffraction Pattern from Black Island Shown

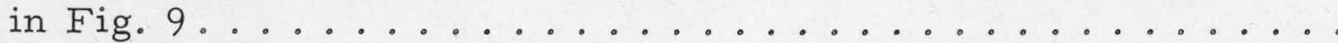




\title{
GROWTH AND ANNEALING OF EVAPORATED \\ ALUMINUM-SILICON FILMS
}

by

R. K. Hart and D. G. Pilney

\begin{abstract}
The growth and annealing of aluminum films containing up to $3 \%$ * silicon have been studied by electronmicroscope and electron-diffraction methods. The films were prepared by condensing the vapors from heated aluminumsilicon alloys onto rock-salt substrates. The textures and defect structures observed in these films, both before and after annealing, are discussed.
\end{abstract}

\section{INTRODUCTION}

Thin, evaporated films have been used in many investigations in recent years to study the interaction between two or more metal components. These multicomponent films can be prepared in a variety of ways ${ }^{1}$ and thus allow considerable flexibility in the choice of method that will be most suitable for a particular application.

Evaporated aluminum-silicon films were chosen for the present investigation since work done in this laboratory ${ }^{2}$ with aluminum alloys has shown that their corrosion behavior in high-temperature water is influenced to an appreciable extent by small changes in silicon content. These alloys contain either less than $0.1 \% *$, or $0.1-0.2 \%$ silicon.

Preliminary experiments, in which standard evaporating techniques were used, indicated that silicon could only be evaporated with great difficulty and that the films were contaminated with oxidation products and filament material; subsequent to this work, electron-beam evaporators, operating in ultrahigh vacuum, have become available, and by this means silicon can be readily evaporated. ${ }^{3}$

Thus it was decided to use alloy evaporation for the preparation of aluminum films containing up to $1 \%$ silicon. As there is no exact relationship between the partial vapor pressures of alloy components and the vapor

\footnotetext{
*Compositions are given in weight per cent throughout this paper.
} 
pressure of pure elements, it is difficult to predict the composition. To obtain films with the desired range of silicon contents, alloys containing between 1 and $10 \%$ silicon were used.

In this way, the effect of small additions of silicon on the growth and annealing behavior of aluminum films was studied.

\section{EXPERIMENTAL PROCEDURE}

All evaporated films were prepared in a conventional vacuumevaporator system, which used an oil-diffusion pump and gave an ultimate pressure in the work area of $8 \times 10^{-6}$ Torr. The capacity of the pumping system was high enough to maintain a pressure of $1 \times 10^{-5}$ Torr during an evaporation. Vapors were deposited onto freshly cleaved rock-salt substrates, located $10 \mathrm{~cm}$ above the source. The substrates were maintained at $450^{\circ} \mathrm{C}$ during film deposition by means of a resistance-heated silver block. Some films were condensed at room temperature. The only difference between these and those formed at $450^{\circ} \mathrm{C}$ was a decrease in grain size; annealing these to $450^{\circ} \mathrm{C}$ caused no observable change.

Aluminum films were prepared for comparison purposes by evaporating $8.0 \mathrm{~cm}$ of $0.028 \mathrm{-cm}$-diam aluminum wire from a tungsten filament. The aluminum wire was made from 99.999\% aluminum stock and was evaporated at a rate of $13 \AA /$ sec. Deposited films were approximately $600 \AA$ thick.

Master alloys for preparing evaporated aluminum-silicon films were made up in 200-g melts from high-purity aluminum (99.999\%) and silicon $(99.999+\%)$. These melts contained 1,5 , or $10 \%$ silicon and were prepared in reactor-grade graphite crucibles by vacuum-induction melting at 850 $900^{\circ} \mathrm{C}$ for $1 \mathrm{hr}$. After cooling to $720^{\circ} \mathrm{C}$, each melt was poured into a chilled copper mold with a hot top on it.

Chips from these melts $(0.02 \mathrm{~g})$ were placed in tungsten boats for evaporation of thin films. Although the aluminum-silicon chips rapidly alloyed with tungsten on melting, sufficient chips could be vaporized to give films $600 \AA$ thick. If sufficient care was taken, tungsten boats could be reused two or three times with the tungsten saturated with aluminum-silicon before they finally burned out. Electron diffraction failed to show any tungsten contamination in evaporated films. The silicon content of evaporated films was a little higher when prepared from reused tungsten boats. The silicon content of each evaporated film was determined by chemical analysis. Films for this purpose were deposited onto glass microscope slides located adjacent to the rock-salt substrate and $10 \mathrm{~cm}$ from the source. 
The silicon yield from each starting alloy was found to vary appreciably from evaporation to evaporation. With both 1 and $10 \%$ alloys there appeared to be a tendency towards a $10 \%$ silicon recovery in the evaporated films. When aluminum-5\% silicon was evaporated, the silicon yield varied from 20 to $60 \%$, the emphasis being on the $20 \%$ yield.

After several of these analyses were completed, it was evident that nothing was to be gained in silicon recovery by using aluminum-silicon alloys containing more than $5 \%$ silicon.

Specimen films were removed from their rock-salt substrates under water and then mounted on seven-hole platinum grids. Subsequent annealing of films was carried out in either a vacuum furnace or on the hot stage of a Siemens electron microscope at $550 \pm 20^{\circ} \mathrm{C}$.

\section{EXPERIMENTAL RESULTS}

\section{A. Aluminum Deposits}

Aluminum vapor condensed onto rock salt at $450^{\circ} \mathrm{C}$ produced films that were made up of grains a few thousand Angstroms in size and often contained voids at grain boundaries as shown in Fig. 1. All the films examined were remarkably free from dislocations and other defect structures. Selected-area diffraction patterns from these films (see Fig. 2) showed that these films were predominantly oriented with (001) aluminum in the plane of the film, but with some mosaic texturing between the grains. Additional maxima tended to form a continuous 220-diffraction ring. These diffractions were far less intense than the main Laue spots and were due to a small

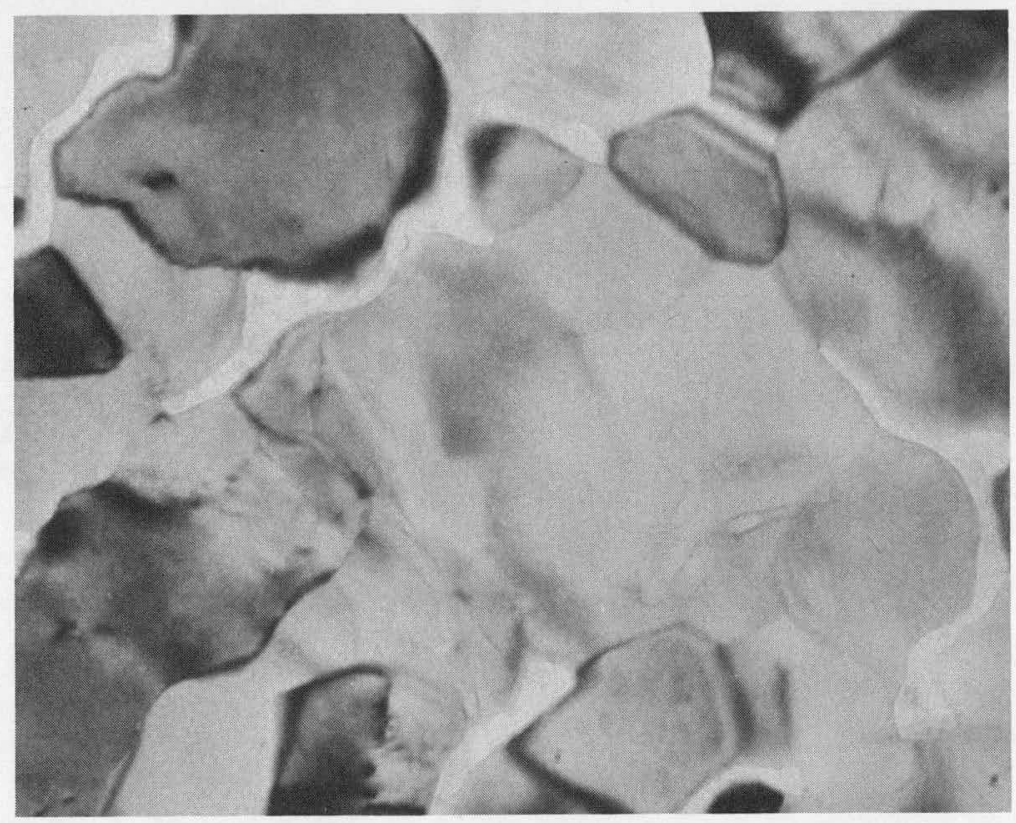

Fig. 1

Aluminum Evaporated onto Rock Salt at $450^{\circ} \mathrm{C}$ 


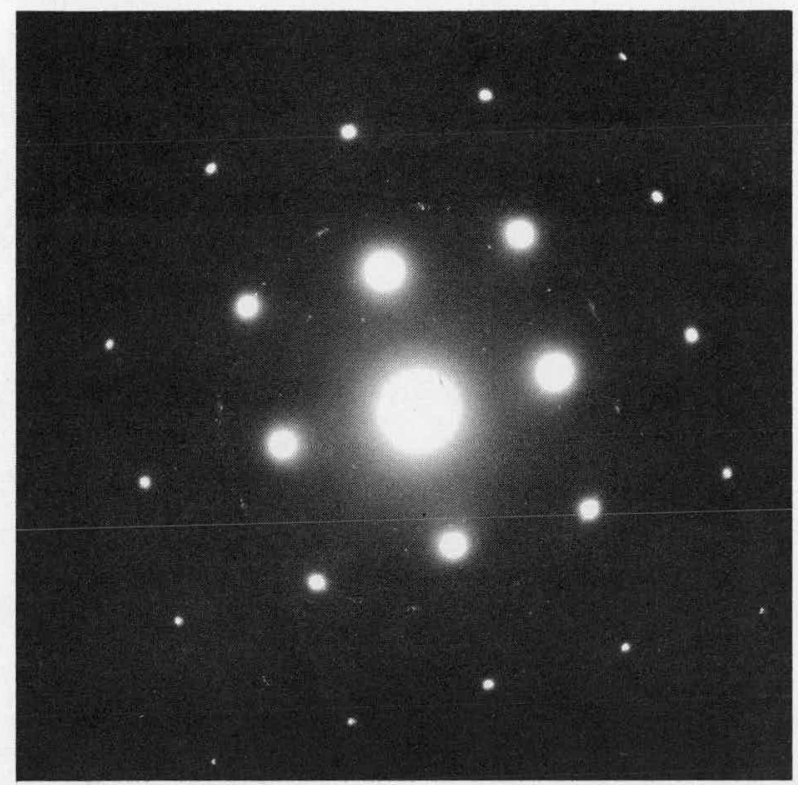

Fig. 2

Selected-area Diffraction Pattern from Film Shown in Fig. 1

101701

$\mathrm{X} 1.5$

amount of aluminum of different texture to the main film. Patterns from aluminum-silicon films contained similar diffraction maxima and are discussed in Section B below.

Annealing these films at $550-560^{\circ} \mathrm{C}$ for $\mathrm{l} \mathrm{hr}$ did not change their appearance or texture.

B. Aluminum-Silicon Deposits

Aluminum-1\% silicon, evaporated onto rock salt, produced continuous films, as shown in Fig. 3, which had a grain size comparable to that of pure aluminum films. Silicon content of these films, by chemical analysis, was around $0.1 \%$; no diffractions due to silicon were observed in electron-diffraction patterns.

The diffraction patterns (see Fig. 4) were, however, noticeably different from those obtained from pure aluminum. These patterns consisted of semicontinuous rings containing 12 equally spaced maxima as well as subsidiary maxima of lower intensity; the relative positions of these maxima are shown in Fig. 5.

These patterns can be interpreted in terms of 111 -oriented grains with $30^{\circ}$ rotations about the film

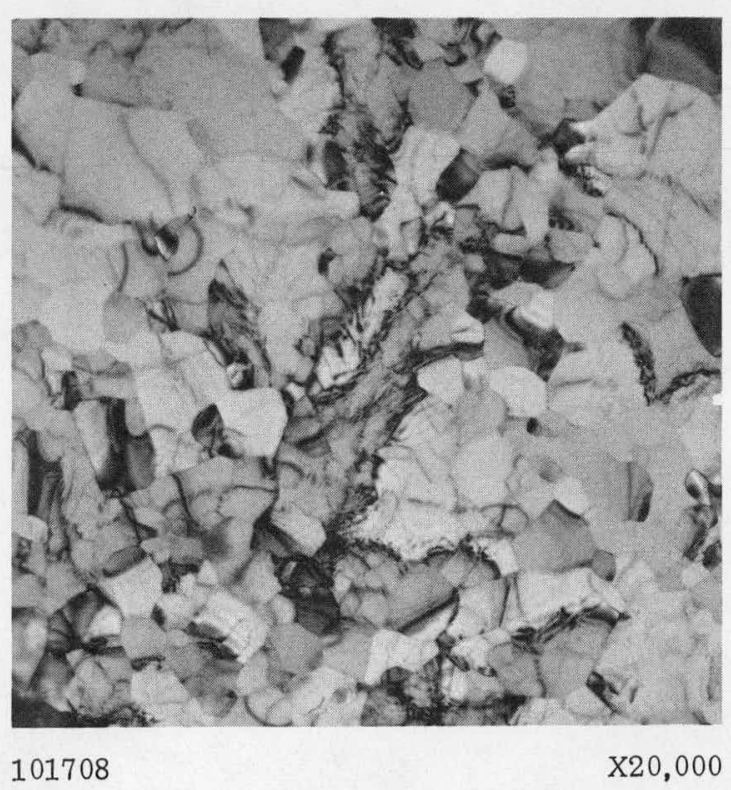

Fig. 3. Aluminum-1\% Silicon Alloy on Rock Salt at $450^{\circ} \mathrm{C}$. (Silicon content of film $0.1 \%$ ) 
normal. In addition, the subsidiary maxima indicate that there is directional spread about specific orientations and, in fact, the films have a tendency toward being fibre-textured.

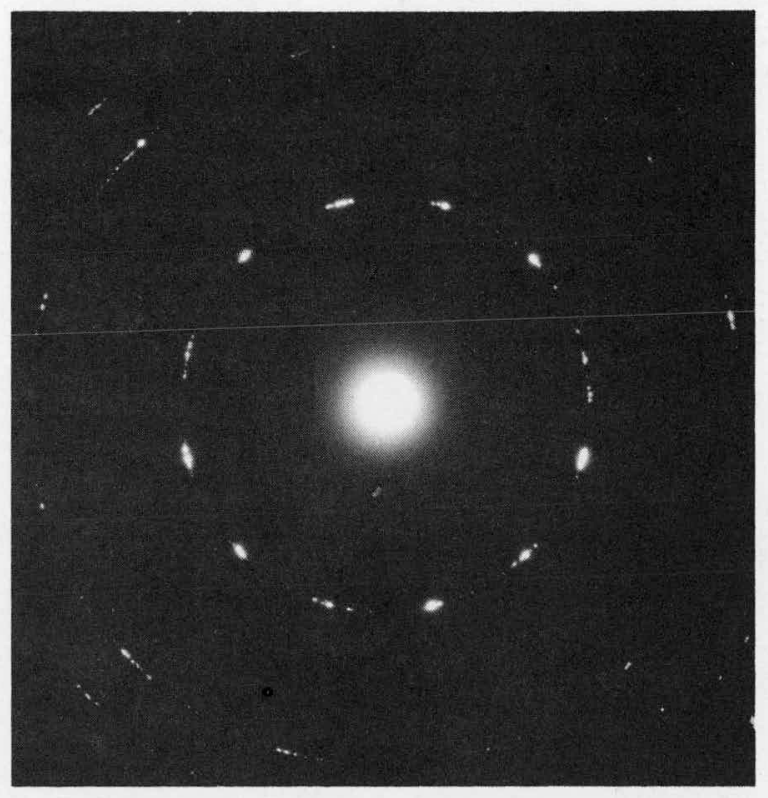

101709
$\mathrm{X} 1.5$

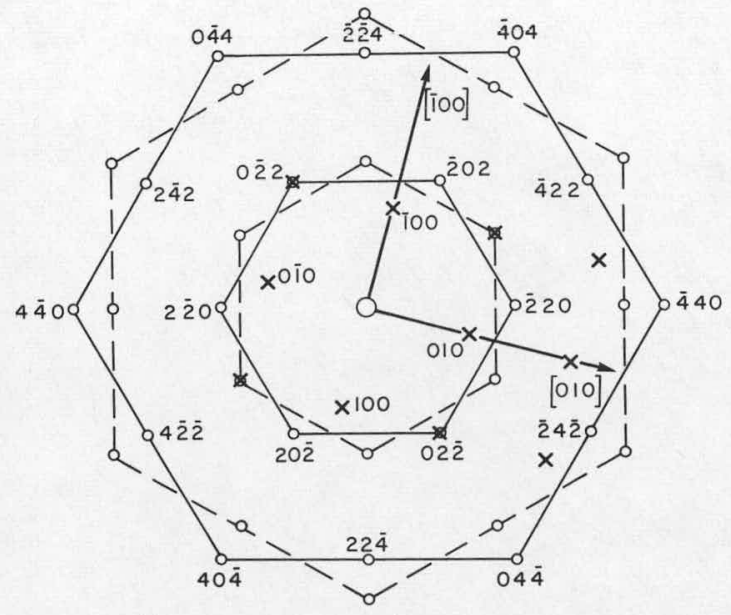

42752

Fig. 5. Schematic Diagram of Pattern Shown in Fig. 4. Additional diffraction maxima from 001-oriented aluminum are indicated by crosses.

Only several films showed any tendency toward epitaxial growth on rock salt. Diffraction patterns from these films were similar to Fig. 4, except they also contained weak spots in cubic array, some of which are indicated by crosses in Fig. 5.

Another difference between films containing $0.1 \%$ silicon and pure aluminum films is shown in Fig. 6. High-magnification micrographs showed that grain boundaries were preferential sites for dislocations and were usually completely delineated by them. These micrographs also showed that dislocation interaction produced a considerable number of subgrains, but other dislocation networks were largely absent from within the grains.

Films produced by evaporation of aluminum-5\% silicon and aluminum-10\% silicon were usually similar, since both deposits contained $1 \%$ silicon. In a few cases, deposits containing as much as $3.3 \%$ silicon were obtained from aluminum-5\% silicon, and these films will be considered separately. 


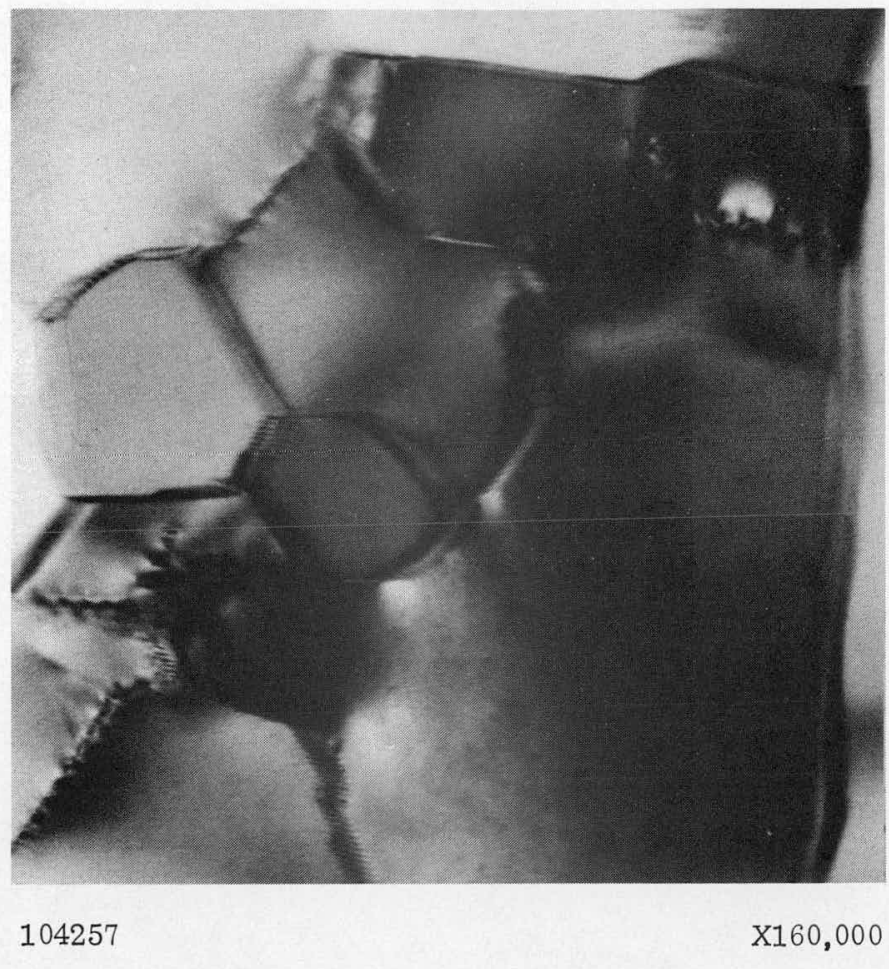

Fig. 6

High Magnification of Aluminum-1\% Silicon Alloy Showing Enhancement of Grain Boundaries by Dislocations

Generally, films containing $1 \%$ silicon had a larger grain size than both those consisting of pure aluminum and those consisting of aluminum plus $0.1 \%$ silicon, but they contained many holes (see Fig. 7), similar to those in pure aluminum films. They grew epitaxially on rock salt at $450^{\circ} \mathrm{C}$ with the (001) in the plane of the film.

lig. 7

Aluminum-10\% Silicon Alloy Fvannrated onto Rock Salt at $450^{\circ} \mathrm{C}$. Silicon content of film approximately $1 \%$.

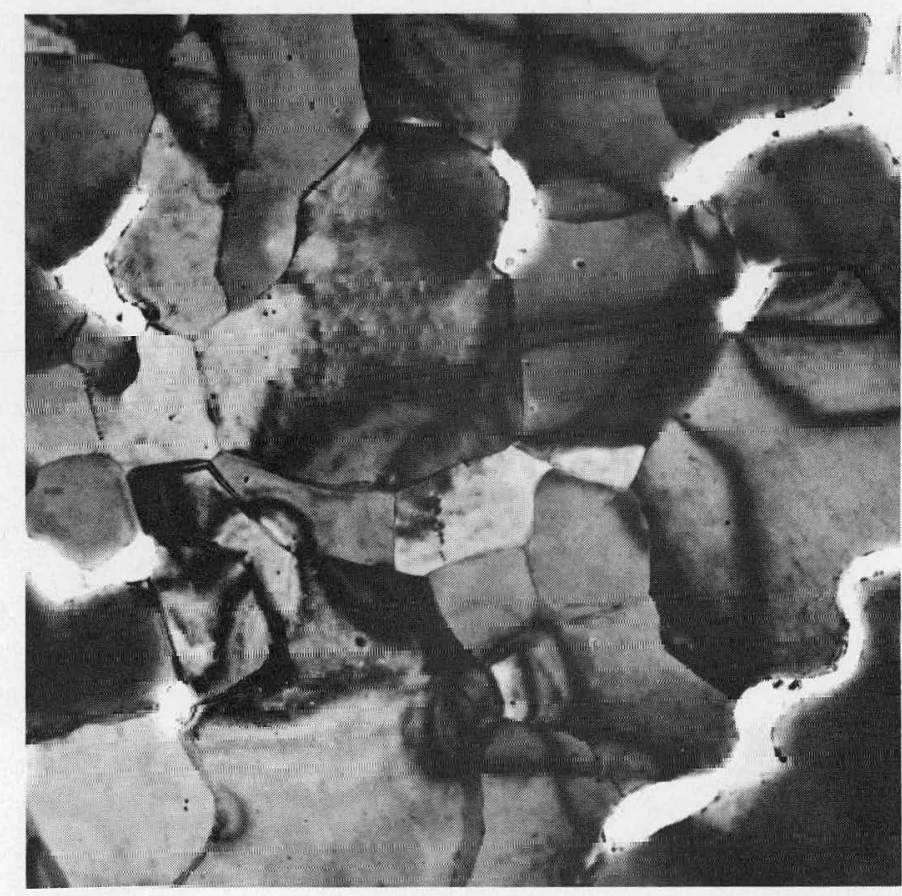


Silicon was well-dispersed in these films as indicated by almostcontinuous spotty rings in electron-diffraction patterns. The relative intensity of silicon diffractions to those due to aluminum increased with increasing silicon content of films.

When deposited films were viewed at high magnification (X80,000), it was observed that grain boundaries were usually clean, although in a few instances dislocation networks similar to those shown in Fig. 6 were observed. Subgraining was present to a lesser extent than in aluminum plus $0.1 \%$ silicon films, but more line dislocations and tangles of dislocations were present within grains.

When the silicon content of evaporated films was $3.3 \%$, the grain size was the largest observed in this investigation; films still contained

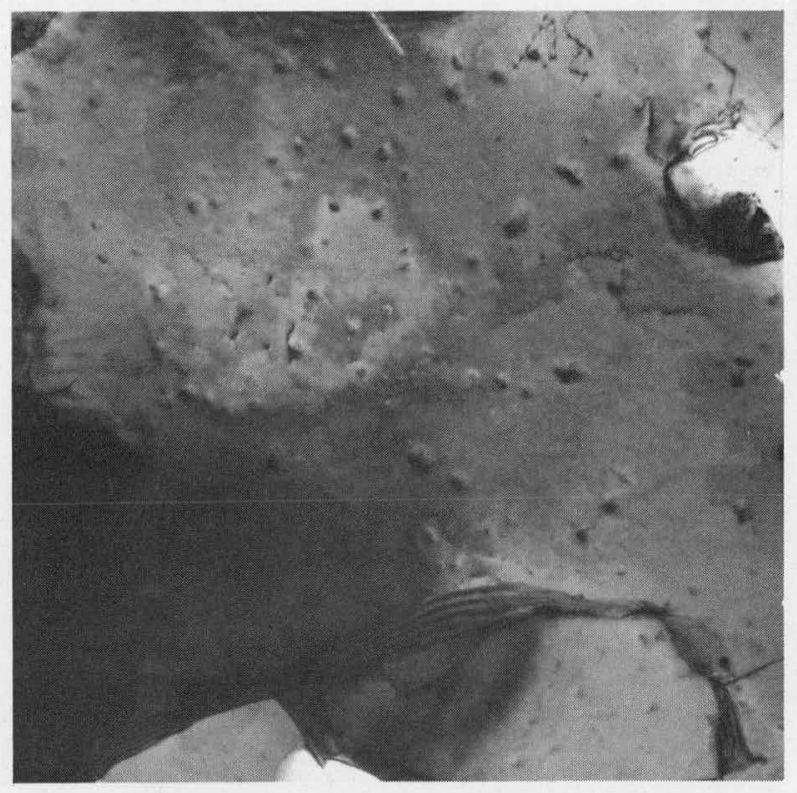

102229

$\mathrm{X} 20,000$

Fig. 8. Aluminum-5\% Silicon Alloy Evaporated onto Rock Salt at $450^{\circ} \mathrm{C}$. Silicon content of film $3.3 \%$. many holes. Many small bumps, shown in Fig. 8, were seen across films having higher silicon content. These features could have resulted from sputtering of the evaporating material and could thus, in part, be responsible for the higher silicon content found in this particular type of film. Dislocations were also numerous in these films, although no preferred sites were evident.

The structure of evaporated aluminum films that contained $0.1 \%$ silicon remained essentially unchanged when the films were annealed at approximately $550^{\circ} \mathrm{C}$. Diffraction patterns from the se films did contain more diffuse scatter around the central spot, which indicated that surface oxide had thickened.

Evaporated aluminum films, containing $1 \%$ silicon and condensed onto rock salt at either room temperature or $450^{\circ} \mathrm{C}$, remained essentially unchanged when heated to approximately $550^{\circ} \mathrm{C}$. Further heating of these films to a little higher temperature and probably not above $570^{\circ} \mathrm{C}$ produced startling changes. The first indication of a change occurring in the specimen was a darkening of the image being viewed, which was similar in effect to when an extinction contour moves across the viewing field.

Up to the time when the image was lost completely from view, there was also a general decrease in clarity of the image. After a few seconds, 
the image became visible again, but completely altered in appearance, as can be seen by comparing Figs. 7 and 9 . It will be noticed that all grain structure has completely disappeared and in its place has appeared a continuous "sea" containing optically opaque islands of material.

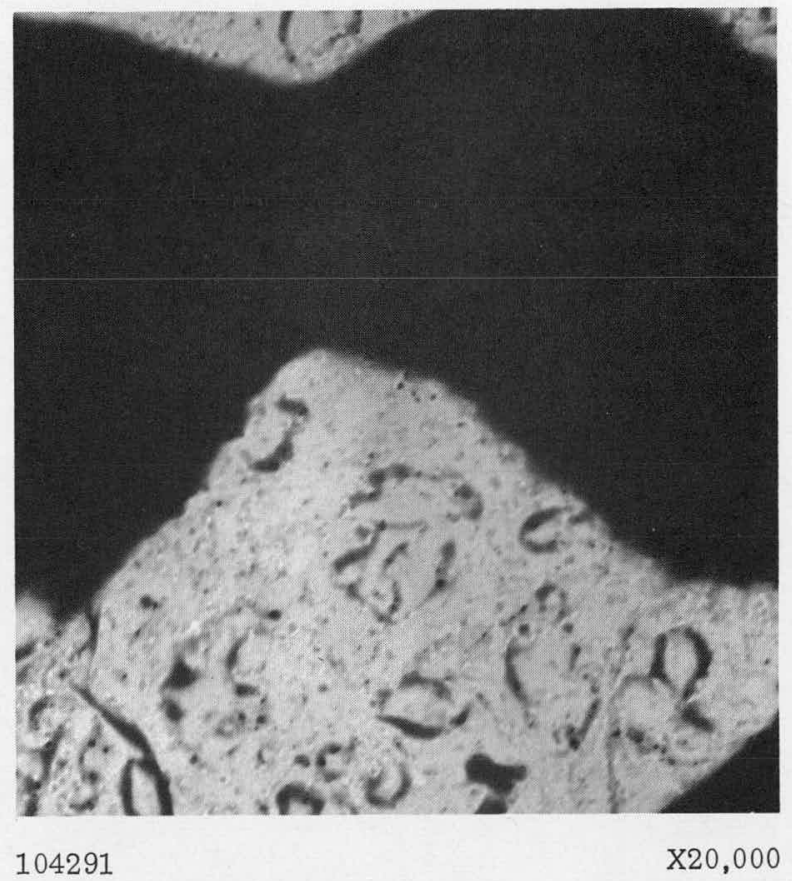

Fig. 9

Aluminum-10\% Silicon Evaporated onto Rock Salt at Room Temperature and Then Heated on Hot Stage at $550 \pm 20^{\circ} \mathrm{C}$. Silicon content of film approximately $1 \%$.

Selected-area diffraction patterns from islands were similar to Fig. 10. The intense, spotty 111 ring of silicon shows that the se islands contain considerably more silicon than the quantity that was uniformly distributed through the initial film. The amount of diffuse scatter around the central spot also increased. This scatter was even more noticeable in diffraction patterns from the adjoining "sea." In fact, diffractions from this area consisted mainly of diffuse scatter and a few isolated spots of relatively low intensity. Some of these spots were aluminum diffractions, while others could be attributed to crystalline $\gamma-\mathrm{Al}_{2} \mathrm{O}_{3}$. In fact, the very fine dot-like features present in the light portions of Fig. 9 give every indication of being crys talline oxide nuclei. The diffuse scatter is most likely due to a

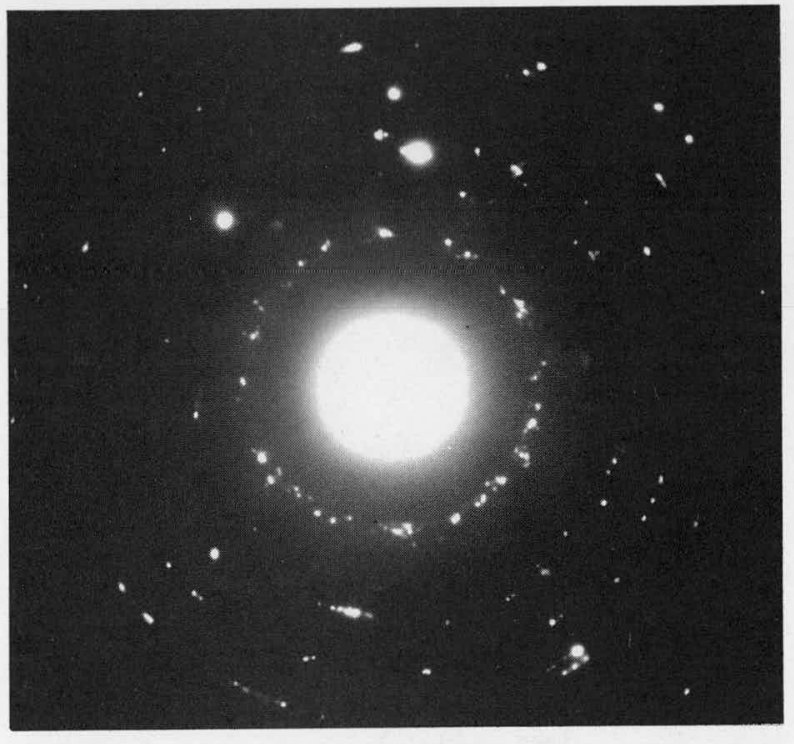

104306

Fig. 10. Selected-area Diffraction Pattern from Black Island Shown in Fig. 9 
much-thickened film of pseudo-amorphous oxide. Micrographs from annealed films of aluminum plus $1 \%$ silicon, as shown in Fig. 9, can be interpreted as the result of the metal film melting and agglomerating into islands by surface-tension forces. The films were prevented from disintegrating by a continuous-oxide film, which is seen as the "sea" in these micrographs. According to the aluminum-silicon phase diagram given by Mondolfo, ${ }^{4}$ when aluminum containing $1 \%$ silicon is heated between 540 and $600^{\circ} \mathrm{C}$, an aluminum solid solution is formed. Above $600^{\circ} \mathrm{C}$, one obtains aluminum plus liquid.

If it is assumed that the above interpretation of electron micrographs is correct, then either aluminum plus $1 \%$ silicon in the form of thin film melts below $600^{\circ} \mathrm{C}$, as shown in the phase diagram, or else the temperature of the specimen in the hot stage, was 30 to $50^{\circ} \mathrm{C}$ hotter than recorded. The latter is a more likely explanation since it is difficult to determine the precise temperature of a specimen in the electron microscope accurately, especially while the specimen is under irradiation from the electron beam.

\section{CONCLUSIONS}

The experiments described here have shown that it is possible to prepare evaporated films of aluminum, containing silicon up to a concentration of $1 \%$, by evaporating aluminum-silicon alloys. Nothing appears to be gained in silicon recovery by evaporating alloys containing more than $5 \%$ silicon.

The presence of $0.1 \%$ silicon disrupted epitaxial growth of aluminum on rock salt at $450^{\circ} \mathrm{C}$ and had a marked effect at grain boundaries. Dislocations were generally concentrated at grain boundaries, although some subgraining and intercrystal dislocations were also observed.

When the silicon content of films was increased to $1 \%$, epitaxy was reestablished with rock salt at $450^{\circ} \mathrm{C}$. At this level, silicon could be detected by electron diffraction. Dislocations were more widely dispersed through these films than they were in films of low silicon content, and dislocation networks at grain boundaries were comparatively rare.

Heating these films to temperatures in the vicinity of $550^{\circ} \mathrm{C}$ or above produced no structural changes unless melting occurred. 


\section{REFERENCES}

1. Weaver, C., and Hill, R. M., Phil. Mag. 8, 375 (1959).

2. Draley, J. E., Ruther, W. E., and Greenberg, S., J. Nuc1. Mat. 6, 157 (1962).

3. Unvala, B. A., and Booker, G. R., Phil. Mag. 9, 691 (1964).

4. Mondolfo, L. F., Metallography of Aluminum Alloys, John Wiley and Sons, New York (1943). 